DOI: https://doi.org/10.47405/aswj.v7i1.197

\begin{tabular}{|c|}
\hline $\begin{array}{c}\text { Asian Social Work Journal (ASWJ) } \\
\text { JOORAAL WORK } \\
\text { (ASW) }\end{array}$ \\
Volume 7, Issue 1, February 2022 \\
\hline \\
\hline
\end{tabular}

\title{
Pilot Study: Feasibility and Preliminary Outcome of the Psychotherapy Intervention with Parents of Leukaemia Children in Malaysia
}

\author{
Muhammad Syamsul Mat Zin', Azlinda Azman', Zarina Abdul Latiff², Loh C-Khai² \\ 1Social Work Programme, School of Social Sciences, Universiti Sains Malaysia (USM), 11800 Penang, Malaysia \\ 2Department of Paeditric, Faculty of Medicine, Universiti Kebangsaan Malaysia (UKM), 56000 Kuala Lumpur, Malaysia \\ Correspondence: Azlinda Azman (azlindaa@usm.my) and \\ Zarina Abdul Latiff (zarinaal@ppukm.ukm.edu.my)
}

\begin{abstract}
Reporting the preliminary findings and the feasibility of a pilot group psychotherapy intervention study of one hour session for four sessions, also known as 'PERKASA Intervention' towards parents of children with leukaemia, conducted at one of the University Teaching Hospital (UTH) in Malaysia. In this Randomized Controlled Trial (RCT) design, a total of 19 parents agreed to participate and 11 participants were placed in the Treatment Group (TG), meanwhile eight parents were placed in the Control Group (CG). This study looked at the effects comparison between pre- and post-interventions, as well as reviewed the feasibility of the implementation of PERKASA Interventions. Feasibility refers to the evaluation of TG participants' feedback. PERKASA Intervention showed to positively impact stress, depression, anxiety, and coping strategies among TG at the pre and post stages. PERKASA Intervention has also been shown that it can be consistently used for targeted groups. The main challenge seen was the recruitment of participants during Covid-19 pandemic occurring all over the world. The data from this pilot study can be used as a reference for larger-scale studies in the future. This intervention was fully conducted by professionals from Medical Social Worker as therapists and the first to be implemented in Malaysia.
\end{abstract}

Keywords: Malaysia Medical Social Work, parents of children with leukaemia, group psychotherapy, RCT

\section{Introduction}

According to Stewart \& Wild (2014), childhood cancer cases are classified as children diagnosed with cancer before reaching the age of 15 and recorded cases of leukaemia, especially acute type, are common cases in children. In Malaysia, boys were the highest recorded compared to girls, $41.4 \%$ and 37.9\% respectively (National Cancer Registration Report 2012-2016, 2019). Although the number of children up to the age of 14 recorded a decrease of $6.6 \%$ over a five-year period, leukaemia remains the main cancer diagnosed among children. It is estimated that 750 to 800 new cases of childhood cancer are detected in Malaysia each year and blood cancer is the highest case recorded (Shuib, 2020).

Parents are the most affected when children are diagnosed with cancer. Parents will feel psychological distress such as stress, depression and anxiety about their children's treatment and future (Rosenberg, Dussel, Kang, Geyer, Gerhardt, Feudtner, \& Wolfe, 2013; van der Geest, van den Heuvel-Eibrink, Passchier, van den Hoed-Heerschop, Pieters, \& Darlington, 2014; Kostak dan Avci, 2013; \& Norberg $\&$ Steneby, 2009). The effects of these psychological stresses will affect the interacting style or also 
known as coping strategies (Hoekstra-Weebers, Wijnberg-Williams, Jaspers, Kamps, \& van de Wiel, 2012).

Besides stress, depression is also recorded as a psychological distress often experienced by parents (Myers, Balsamo, Lu, Devidas, Hunger, Carroll, Winick, Maloney, \& Kadan-Lottick, 2014; \& Haegen and Luminet, 2015). Difficulty of living a life when a child is diagnosed with cancer also causes depression among parents (Wikman, Mattsson, von Essen \& Hoven, 2018). Parents experience symptoms of stress and depression, effects more severely felt by mothers (Masa'Deh, Collier, \& Hall, 2012; \& Barrera, Athenaeum, Doyle, Berlin-Romalis, \& Hancock, 2012). The occurrence of maladaptive behaviour among parents due to increased levels of psychological distress will impact the treatment of children with leukaemia (Farmer \& Lee, 2011). According to Jobe-Shields, Alderfer, Barrera, Vannatta, Currier, and Phipps (2009), when symptoms of depression occurred, children with cancer were also affected by the problem. A greater impact not only for patients, but to the entire family system, including their social system (Kurtz, \& Abrams, 2010).

Anxiety is a common issue among parents of children with leukaemia (Di Battista, Dupuis, Cassidy, Portwine, Johnston, Pradier Silva, Sung, \& Barrera, 2017). Anxiety problems among parents of children with cancer are also caused by concerns of financial issues (Bilani, Jamali, Chahine, Zorkot, Saab, Saab, Nabulsi, \& Chaaya, 2019). Parents' anxiety towards diagnosis and prognosis of their children were also identified as factors that can lead to the use of emotional-focus coping strategies (Kohlsdorf \& Costa Junior, 2011), and able to disrupt parents' quality of sleep (McLoone, Wakefield, Yoong, \& Cohn, 2013). This psychological distress is identified to occur continuously as some parents still practice maladaptive behaviour patterns during childhood cancer diagnoses and will continue even after the essential treatment has been completed (Williams, McCarthy, Eyles, \& Drew, 2013). A greater impact affects not only to patients, but to the entire family system, also including their social system (Kurtz \& Abrams, 2010).

In Malaysia, stress studies among parents of children with leukaemia or cancer are limited. Zarina, Radhiyah, Hamidah, Rahman, and Syed Zulkifli, (2012) found that the stress level of parents of children with leukaemia was $27.3 \%$. Although the percentage rate is low, the study has proven that some parents experienced stress when their child is diagnosed with leukaemia. The study contrasts with studies by Othman, Mohamad, Hussin, and Blunden (2011a) which found stress levels among parents of children with cancer were high. The findings differences in this study needs to be viewed as a knowledge perspective because stress levels will change from the first day a child is diagnosed with a chronic disease (Osborne, McHugh, Saunders, \& Reed, 2008). However, both studies proved that dimensions of stress experienced by parents affected behavioural patterns and require specific actions or interventions to overcome it (Othman, Mohamad, Hussin, and Blunden, 2011b).

Studies on anxiety in the parents of children with cancer or leukaemia in Malaysia also limited. However, studies from Ambigga Devi, Sherina, and Suthahar, (2005) proved caregivers of cancer patients experienced anxiety problems while receiving treatment in Kuala Lumpur, Malaysia. Din, Jaafar, Zakaria, Saini, Ahmad, and Midin (2017) also found caregivers' anxiety problems with breast cancer patients impacted the treatment of patients.

Sutan, Al-Saidi, Latiff, and Ibrahim (2017) have identified the use of coping strategies among parents of children with leukaemia in Malaysia. Study found that majority parents using problem-focus coping strategies and only focused on religious factors. Although the findings showed that problem-focus coping strategies is used by parents, the relationship with the quality of life related is still at a low level. These parents were still exposed to various psychosocial threats and derive them for the use of emotion-focus coping strategies if no specific interventions were implemented to improve the cognitive ability to deal with emotionally disturbing situations. A study by Nur Saadah, Siti Hajar, and Islam, (2014) found that most of the mothers of children with chronic diseases implemented emotion-focus coping strategies due to overthinking expectations in the future.

Hence, parents of children with cancer need continuous appropriate psychotherapy interventions to improve family well-being (Kearney, Salley, \& Muriel, 2015). There are among parents who conceal 


\section{Asian Social Work Journal (ASWJ), Volume 7, Issue 1, (page 11 - 23), 2022 \\ DOI: https://doi.org/10.47405/aswj.v7i1.197}

their feelings about their child's disease (Watanabe, Nunes, \& Abreu, 2014). Lakkis, Khoury, Mahmassani, Ramia, and Hamadeh (2016) proved that parents with psychological problems and not given early intervention after child diagnosed with cancer, are prone to use maladaptive response strategy.

Psychotherapy interventions to help parents overcome their psychological problems should be implemented, as suggested by American Academy of Paediatrics (1997). It aimed to control symptoms of stress, anxiety, depression, and being able to use appropriate coping strategies in environment. Psychotherapy interventions implementation to parents of children with cancer were also agreed by Rosenberg, Wolfe, Bradford, Shaffer, Yi-Frazier, Curtis, Syrjala and Baker, (2014) to lower the risk of psychological distress.

Therefore, this conducted study provided three significant benefits; first: implementation of the first group psychotherapy approach in Malaysia using the RCT design towards parents of children with leukaemia; second: enhance the professionalism of Medical Social Workers in Malaysia; and third: this study can become a reference to similar studies in the future, particularly in Malaysia.

\section{Methodology}

\section{Location}

This study was conducted at one of the eminent University Teaching Hospital (UTH) which operates in the Kuala Lumpur, Malaysia. This hospital is under the supervision of the Malaysia Ministry of Higher Education (MOHE). This UTH has often been the main reference for health services and at the same time becomes the medical research centre. Therefore, studies on the implementation of psychotherapy interventions on parents of children with leukaemia were conducted in accordance with the guidelines, ethics and regulations set. Permission to conduct research at this hospital was obtained with the approval by Hospital Research Ethics Committee.

\section{Participants}

The samples were selected through an RCT approach, controlled by an Oncology/Haematology Paediatrician. This study uses a non-probability sampling approach through purposive sampling techniques. The study consisted of parents of children with cancer not more than 12 months after being diagnosed, able to speak and read in the Malay language, never had an accident involving a head injury that might affect cognitive function, and children with cancer not more than 18 years of age.

\section{Measures}

The study examined four major variables: stress, depression, anxiety, and coping strategies. For stress testing, researchers used the Parental Stress Index-Short Form (PSI-SF) instrument; anxiety and depression testing using the Hospital Anxiety and Depression Scale (HADS) instrument, while coping strategies used the Brief COPE (B-COPE) instrument. The validity and reliability of all these instruments has been proven to be used in Malay version.

\section{Parental Stress Index-Short Form (PSI-SF)}

This parent-child based instrument focuses on two main aspects, namely child characteristics and parental characteristics (Loyd \& Abidin, 1985). The instrument was translated to native language and was tested for reliability (Zarina et al., 2012). Since this study looked at overall stress levels, the method is summing up the overall score from 36 questions to determine stress levels among all samples involved (Aracena, Gomez, Undurraga, Leiva, Marinkovic, \& Molina, 2016). 


\section{Hospital Anxiety and Depression Scale (HADS)}

HADS was introduced to test levels of anxiety and depression in hospitals by Zigmond and Snaith (1983). This instrument is divided into two main sectors of anxiety and depression. Reliability and validity of this instruments has been tested in Malaysian hospital setting, and shows consistent outcome (Lin \& Wong, 2012).

\section{Brief COPE (B-COPE)}

Coping strategies is the part that involves a person's behaviour when dealing with a situation in an environment (Lazarus \& Folkman, 1984), whether it is the use of problem-focus coping strategies or emotion-focus coping strategies. This instrument contains 28 questions that have been modified from the original long version and might affect interest to the respondents involved due to the time factor (Carver, 1997). The Malay version of the B-COPE instrument used in this study has been proven to be reliable and valid among parents of leukaemia children in Malaysia (Sutan et al., 2017).

\section{Design}

The study is action-based research, designed specifically to address psychological issues among parents of children with leukaemia. The study used the RCT approach which had two arms, Treatment Group (TG) and Control Group (CG) respectively. This study refers to the previous study, Surviving Cancer Competently Intervention Program (SCCIP), which was conducted by Kazak, Simms, Barakat, Hobbie, Foley, Golomb, and Best (1999). SCCIP has been recognized as one of the 19 best intervention programs in the United States (National Cancer Institute, n.d.). In addition, a psycoeducation study on parents of children with cancer in Malaysia has also been referred for the development of this study (Othman, Blunden, Mohamad, Mohd Husin, Jamil Othman, 2010).

\section{Procedure}

Population group was approached by a Medical Social Worker and assisted by two Ward Managers, to explain the intervention structure; and was rigorously monitored by an Oncologist-Hematologist Paediatrics appointed. Parents who agreed to participate in the study were provided with a consent form to be signed and distributed the T1 questionnaire set. RCT was implemented after the parent agreed to participate in the study. TG was given the schedule of the intervention session, while CG remained with normal daily routine at the hospital or at home if there is no hospital treatment appointment given.

The T2 questionnaire set was distributed after the end of the intervention session to ensure that all participants had the opportunity to return the questionnaire set before leaving the location. This was aimed to reduce the impact of time interaction of the groups involved in this study. In addition, all participants from TG were also distributed a set of Participants Feedback Form for the program. All participants from TG provided all activities needs, containing a set of notes for all session, stationery, and face shield to comply with Covid-19 prevention safety protocols. Activities were carried out in the Paediatrics Department Playroom. During the session, the playroom was closed to make sure the confidentiality of all participants involved.

\section{The Intervention}

This intervention known as 'PERKASA Intervention' (Empowerment Intervention) in the native language, a new group psychotherapy intervention in Malaysia and was developed specifically for parents of children with leukaemia. Intervention PERKASA are using approaches from Stress and Coping Strategies Theory (Lazarus \& Folkman, 1984) and Rational Emotive Behavioural Therapy Theory (Ellis 1995). PERKASA Intervention emphasize emotional aspects; rational belief; cognitive; behaviour; and a part of psychoeducation aspects (Othman et al., 2010; \& Warne, Ludwig, Sweeney, Spillane, Hogan, Ryan, \& Carol, 2011). This intervention uses an interactive conversational approach instead of an interview method to avoid boredom among participants. PERKASA Intervention contains 
DOI: https://doi.org/10.47405/aswj.v7i1.197

four sessions and lasts 60 minutes per session. This brief intervention was able to drive the success of intervention goal more effectively.

\section{Session I: Introduction (60 minutes)}

In this session, six main structures include rapport building; Introduction of PERKASA Intervention; Concept of A-B-C; Leukaemia: Lightning on a Beautiful Day (Metaphor approach); what is the Disturbance and Coping Strategies; and Session I Conclusion and Postponement.

\section{Session II: Belief (60 minutes)}

Session II covered four main activities covering a brief review of Session I; Rational Beliefs; Irrational Beliefs; and Summary and Postponement of Session II. This session is an important session that needs to be mastered by each participant from TG.

\section{Session III: Consequences (60 minutes)}

In this session, there were four main activities, covering a brief discussion of Session II; discussion of effects on Emotions; Behaviour; Cognitive; and Summary and Postponement of Session III. Participants from TG were also taught about the possible effects they might face in the future if negative emotions were not successfully managed at an early stage.

\section{Session IV: Conclusion (60 minutes)}

In this last session, there were nine activities for parents of children with leukaemia in TG. Activities in Session IV encompasses: Brief discussion of Session III; Summary of A-B-C concepts, Summary of Interference \& Coping Strategies, Summary of Rational Beliefs, Summary of Irrational Beliefs, Summary of Effects on Emotions, Behaviour, and Cognitive; and Summary \& Closing of Session IV. In this session, the interventionist will summarize all the sessions conducted, and will interact with all participants about their reactions and feelings throughout participating in this intervention

\section{Result}

A total of 11 participants $(\mathrm{N}=11)$ in $\mathrm{TG}$ and eight $(\mathrm{N}=8)$ participants in $\mathrm{CG}$. This pilot study began on 25 March 2021 and was terminated on 31 May 2021 following the announcement by the Government of Malaysia for the implementation of the Movement Control Order (MCO) total lockdown starting 1 June 2021 (Prime Minister Media Statement Office, 28 May 2021).

A total of 32 parents of children with leukaemia were approached to participate in this pilot study. However, only 19 parents agreed to participate in the study and had signed a consent to participate in the study, 11 participants each in the TG, while the remaining eight parents were placed in the CG.

A total of 11 participants from the TG sample group consisted of six males (54.5\%) and 5 females $(45.5 \%)$. The males and females who participated in this study were termed as mothers or fathers. The mean age for TG was 36.5 (5.61) and the age ranged from 28 to 47 years. A total of $90.9 \%$ of the participants from TG were Malays, while the remaining 9.1\% (one participant) were other races. Eight out of $11 \mathrm{TG}$ participants or equivalent to $72.7 \%$ were employed while the remaining three were unemployed (27.3\%). Both groups showed a balanced age of children, the mean age was 6.7 (3.29) for TG and the mean age for CG children was 5.8 (3.27). The mean duration of a child suffering from leukaemia for TG and CG was 7.8 (3.25) and 8.3 (3.54), respectively.

Table 2 shows the findings of the study within TG at the T1 and T2 levels. It was found that the mean value of participants' stress level decreased by $13.74 \%$ (T1: $\mathrm{M}=117.36, \mathrm{SD}=3.96 ; \mathrm{T} 2: \mathrm{M}=103.18$, $\mathrm{SD}=3.46, d=3.82$ ). This size effect test analysis was categorized as large and has proven that there was a good interaction effect on PERKASA Intervention and the stress within TG. Meanwhile 
DOI: https://doi.org/10.47405/aswj.v7i1.197

measurements of anxiety using the HADS inventory found large size effect values $(d=1.79)$ from the $\mathrm{T} 1$ to T2 levels. The effect of this pilot intervention has successfully reduced $19.9 \%$ of the anxiety levels in TG participants. Comparative analysis has proven that this intervention has also successfully reduced the level of depression within TG by $19.4 \%$. The last aspect tested was the coping strategies. At the T1 level, the mean value was 66.18 (3.63), while the mean value at the T2 level was 70.27 (3.88).

Figure 1. Consort Diagram

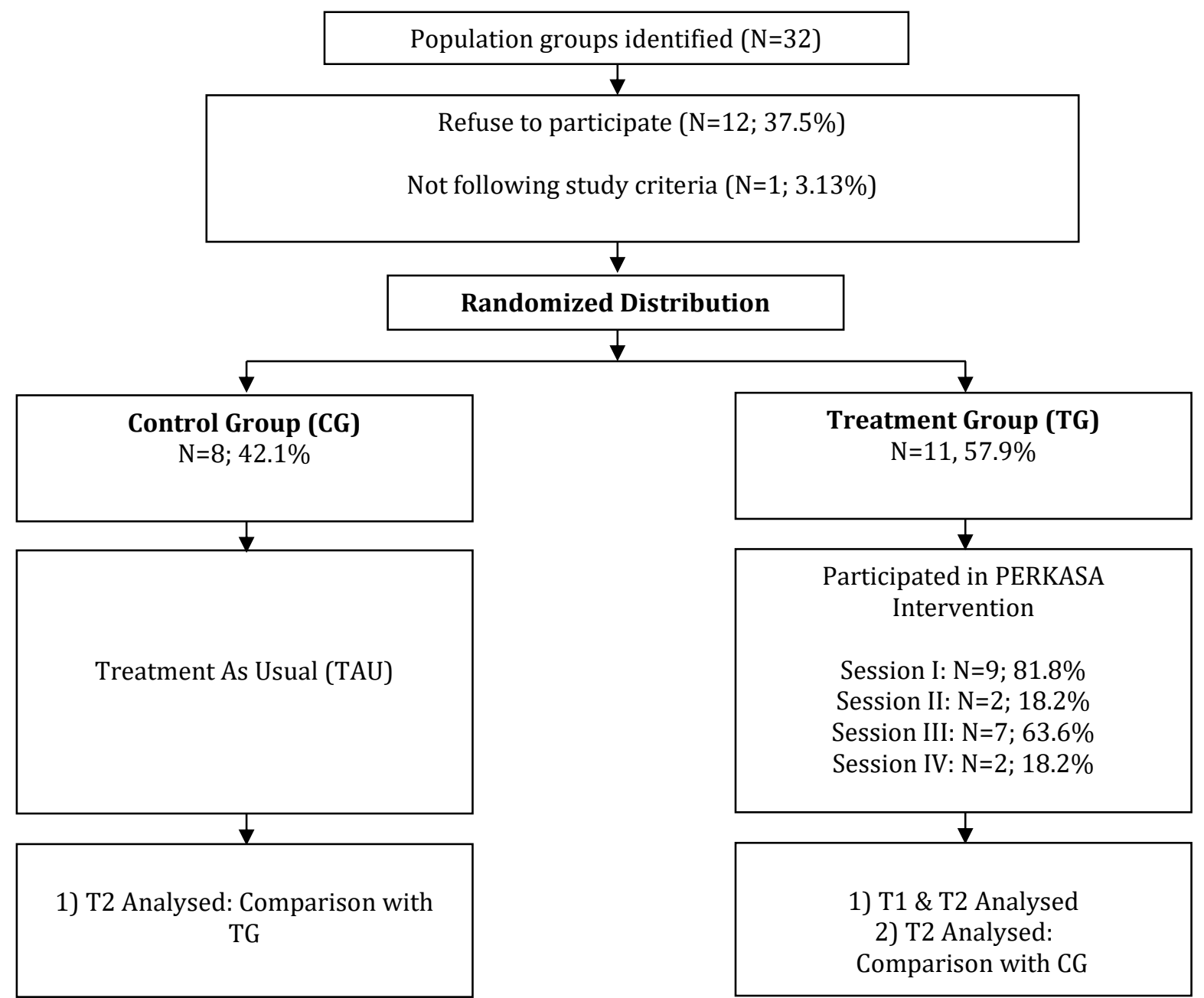

Table 1. Demographics of Treatment Group (TG) and Control Group (CG)

\begin{tabular}{lcc}
\hline Demographics & TG $(\mathbf{N}=\mathbf{1 1}) / \%$ & $\mathbf{C G}(\mathbf{N}=\mathbf{8}) / \%$ \\
\hline Gender & $\mathrm{N}=6(54.5 \%)$ & $\mathrm{N}=4(50 \%)$ \\
Male & $\mathrm{N}=5(45.5 \%)$ & $\mathrm{N}=4(50 \%)$ \\
Female & $\mathrm{M}=36.5 / \mathrm{SD}=5.61$ & $\mathrm{M}=35.9 / \mathrm{SD}=3.18$ \\
Age & Age range $=28-47$ years & Age Range $=31-41$ years \\
Race & $\mathrm{N}=10(90.9 \%)$ & $\mathrm{N}=8(100 \%)$ \\
Malay & $\mathrm{N}=1(9.1 \%)$ & \\
Others & $\mathrm{N}=8(72.7 \%)$ & $\mathrm{N}=6(75 \%)$ \\
Working Status & $\mathrm{N}=3(27.3 \%)$ & $\mathrm{N}=2(25 \%)$ \\
$\begin{array}{l}\text { Unemployed } \\
\text { Income/Month } \\
\text { No Income }\end{array}$ & $\mathrm{N}=3(27.3 \%)$ & $\mathrm{N}=2(25 \%)$
\end{tabular}


DOI: https://doi.org/10.47405/aswj.v7i1.197

$\begin{array}{lcc}\text { RM1001-RM3000 } & \mathrm{N}=1(9.1 \%) & \mathrm{N}=2(25 \%) \\ \text { RM3001-RM5000 } & \mathrm{N}=3(27.3 \%) & \mathrm{N}=3(37.5 \%) \\ \text { More than RM5001 } & \mathrm{N}=4(36.4 \%) & \mathrm{N}=1(12.5 \%) \\ \text { Secondary } & & \\ \text { Diploma } & \mathrm{N}=4(36.4 \%) & \mathrm{N}=2(25 \%) \\ \begin{array}{l}\text { Degree } \\ \text { Masters }\end{array} & \mathrm{N}=5(45.5 \%) & \mathrm{N}=3(37.5 \%) \\ \text { Location of Residence } & \mathrm{N}=2(18.2 \%) & \mathrm{N}=2(25 \%) \\ \text { In Selangor/KL } & - & \mathrm{N}=1(12.5 \%) \\ \begin{array}{l}\text { Outside Selangor/KL } \\ \text { (Outside Negeri Selangor/KL) }\end{array} & \mathrm{N}=10(90.9 \%) & \mathrm{N}=7(87.5 \%) \\ \text { Negeri Sembilan } & \mathrm{N}=1(9.1 \%) & \mathrm{N}=1(12.5 \%) \\ \text { Age of children with leukaemia } & \mathrm{N}=1(100 \%) & \mathrm{N}=1(100 \%) \\ \text { Duration of having leukaemia } & \mathrm{M}=6.7 / \mathrm{SD}=3.29 & \mathrm{M}=5.8 / \mathrm{SD}=3.27 \\ & \mathrm{M}=7.8 / \mathrm{SD}=3.25 & \mathrm{M}=8.3 / \mathrm{SD}=3.54\end{array}$

Table 2. Participants Data of Treatment Group (TG) at T1 and T2

\begin{tabular}{lcccc}
\hline \multicolumn{1}{c}{ TG } & M (SD) & F & df & $\boldsymbol{d}$ \\
\hline PSI T1 & $117.36(3.96)$ & $149.85^{*}$ & 1,10 & 3.82 \\
PSI T2 & $103.18(3.46)$ & & & \\
HADS-Anxiety T1 & $18.18(1.66)$ & $72.73^{*}$ & 1,10 & 1.79 \\
HADS-Anxiety T2 & $14.55(2.38)$ & & & \\
HADS-Depression T1 & $13.09(3.18)$ & $35.64^{*}$ & 1,10 & 0.91 \\
HADS-Depression T2 & $10.55(2.38)$ & & & \\
COPE T1 & $66.18(3.63)$ & $8.11^{*}$ & 1,10 & 1.09 \\
COPE T2 & $70.27(3.88)$ & & & \\
& & & \\
\hline
\end{tabular}

As the coping strategy is divided into two main dimensions, a detailed analysis (Table 3 ) has found that participants in TG have successfully increased by $14.2 \%$ problem-focus use and the effect size is $d$ $=0.89$. The second aspect tested for coping strategies was emotional-focus use and there was a decrease of $4.6 \%$ post-session.

Table 3. Coping Strategies Data of Treatment Group (TG) at T1 and T2

\begin{tabular}{lcccc}
\hline \multicolumn{1}{c}{ TG } & M (SD) & F & df & $\boldsymbol{d}$ \\
\hline COPE-Problem T1 & $2.33(0.22)$ & $19.71^{*}$ & \multirow{2}{*}{1,10} & 0.89 \\
COPE-Problem T2 & $2.66(0.51)$ & & & \\
COPE-Emotional T1 & $2.41(0.95)$ & $5.54^{*}$ & 1,10 & 0.19 \\
COPE-Emotional T2 & $2.3(0.19)$ & & \\
\hline
\end{tabular}

N=11; T1: Pre-Intervention; T2: Post-Intervention; $d$ : Effect Size

Statistical Technique: Repeated Multivariate Anova test

${ }^{*} p<0.05$

Table 4 is the findings of the T2 level comparison between the tested groups. There was a significant difference between the stress levels of TG and CG. Additionally, participants from TG were found to be better than CG in anxiety and depression. Nevertheless, the data show that there is no significant difference between these two variables. The last variable tested was the comparison of coping strategies. Analysis found TG is better than CG in coping strategies. Although there was a large size effect $(d=0.87)$, the analysis found no significant difference between the two. Table 5 shows in depth the differences in the use of coping strategies between the two groups tested. Although there was no significant difference between these two groups, it was found that the use of problem-focus coping strategies and emotion-focus coping strategies among TG was better than CG. 
Table 4. Comparison Between Treatment Group (TG) and Control Group (CG) at T2

\begin{tabular}{|c|c|c|c|c|c|c|}
\hline & \multicolumn{2}{|c|}{$\begin{array}{c}\text { TG } \\
(\mathrm{N}=11)\end{array}$} & \multicolumn{2}{|c|}{$\begin{array}{c}C G \\
(\mathrm{~N}=8)\end{array}$} & \multirow[t]{2}{*}{$t$} & \multirow[t]{2}{*}{$d$} \\
\hline & $\mathbf{M}$ & SD & $\mathbf{M}$ & SD & & \\
\hline PSI & 103.18 & 3.46 & 117.63 & 2.38 & $-6.61 *$ & 4.78 \\
\hline HADS Anxiety & 14.55 & 2.38 & 16.63 & 2.45 & -1.86 & 0.86 \\
\hline HADS Depression & 10.55 & 2.38 & 11.25 & 1.83 & -0.69 & 0.33 \\
\hline COPE & 70.27 & 3.88 & 67.25 & 2.92 & 1.85 & 0.87 \\
\hline
\end{tabular}

T2: Post-Intervention; $d$ : Effect Size

Statistical Technique: Independent sample t-test

${ }^{*} p<0.05$

Table 5. Comparison of Coping Strategies Use Between Treatment Group (TG) and Control Group (CG) at T2

\begin{tabular}{cccccccc}
\hline & \multicolumn{2}{c}{$\begin{array}{c}\text { TG } \\
(\mathbf{N}=\mathbf{1 1})\end{array}$} & \multicolumn{2}{c}{ CG } & (N=8) & $\boldsymbol{t}$ & $\boldsymbol{d}$ \\
& $\mathbf{M}$ & $\mathbf{S D}$ & $\mathbf{M}$ & $\mathbf{S D}$ & & \\
\hline COPE-Masalah & 2.66 & 0.15 & 2.46 & 0.14 & $2.98^{*}$ & 0.15 \\
COPE-Emosi & 2.3 & 0.19 & 2.32 & 0.19 & -0.23 & 3.23 \\
\hline
\end{tabular}

T2: Post-Intervention; $d$ : Effect Size

Statistical Technique: Independent sample t-test

${ }^{*} p<0.05$

\section{Acceptability Feedback of PERKASA Intervention}

This feedback is pivotal to improve any possibilities, safety, and acceptance of the PERKASA Intervention program. The program's feedback scoring uses the open-ended question method and consisted of 10 questions. The feedback evaluation of the pilot study used only basic statistics analysis to look of the percentage of sample acceptance of PERKASA Intervention, without using high statistical techniques such as descriptive and inferential analysis.

Table 6. Percentage (\%) of Participants Acceptance Feedback Towards PERKASA Intervention

\begin{tabular}{|c|c|}
\hline No. & Questions \\
\hline 1 & $\begin{array}{l}\text { I learned something important from this program } \\
\text { Yes }=\mathbf{1 0 0 \%} ; \mathbf{N o}=\mathbf{0 \%}\end{array}$ \\
\hline 2 & $\begin{array}{l}\text { The topics described are important } \\
\text { Yes }=\mathbf{1 0 0 \%} ; \text { No }=\mathbf{0 \%}\end{array}$ \\
\hline 3 & $\begin{array}{l}\text { This program helps me interact better with my family and my environment } \\
\text { Yes }=100 \% ; \mathbf{N o}=\mathbf{0} \%\end{array}$ \\
\hline 4 & $\begin{array}{l}\text { The notes provided in this program are adequate } \\
\text { Yes }=\mathbf{8 1 . 8 \%} \% \text {; No }=\mathbf{1 8 . 2 \%}\end{array}$ \\
\hline 5 & $\begin{array}{l}\text { This program is interesting and interactive } \\
\text { Yes }=90.9 \% ; \text { No }=9.1 \%\end{array}$ \\
\hline 6 & $\begin{array}{l}\text { Four sessions in this program are appropriate } \\
\text { Yes }=90.9 \% ; \text { No }=9.1 \%\end{array}$ \\
\hline 7 & $\begin{array}{l}\text { The time allocated for each session is appropriate } \\
\text { Yes }=\mathbf{6 3 . 6 \%} \text {; No }=\mathbf{3 6 . 4 \%}\end{array}$ \\
\hline 8 & $\begin{array}{l}\text { The Intervention Therapist handled each session well } \\
\text { Yes }=\mathbf{1 0 0 \%} ; \mathbf{N o}=\mathbf{0 \%}\end{array}$ \\
\hline 9 & Programs like this can help other parents in the future \\
\hline
\end{tabular}


Yes $=100 \% ;$ No $=\mathbf{0 \%}$
10 I will tell other parents who have children with leukaemia to join this program in the future

Yes $=100 \% ;$ No $=0 \%$

Although this program is the first group intervention program implemented for parents of children with leukaemia in Malaysia, the acceptance of participants to this program is very encouraging. The time aspect was identified as a factor that most answered "No" (36.4\%) by the participants. A review of the participants' written comments found that the 60-minute period was quite long as they had to manage the child who was being treated in the hospital and at the same time had to manage other matters. Other written comments were 'the place is not suitable and needs to use wider space', 'the organizers need to prepare a light meal after the end of each session'. Overall, most participants accepted and agreed with the implementation of the PERKASA Intervention program.

\section{Discussion}

This pilot study of PERKASA Intervention has shown success for parents of children with leukaemia who have psychological distress when they knew their child has been diagnosed with leukaemia. The parents' involvement in this pilot study was $59.4 \%$ and lower than other studies (Anclair, Lappalainen, Muotka, \& Hiltunen, 2018). The Covid-19 factor that has hit the world and lockdown implementation by the Malaysian Government has also limited the movement and timeframe for recruitment of the target group. However, feedback from participants who have participated in PERKASA Intervention is the key to the implementation of this program in the future. The percentage of acceptance of the PERKASA Intervention is good. The duration of intervention implementation is seen as an important aspect to be re-evaluated as appropriate in the future.

Getting respondents to participate in RCT studies is difficult and is a critical issue (Marsland, Long, Howe, Thompson, Tersak, \& Ewing, 2013). Nevertheless, this difficulty is seen as a challenge to develop a creative method that is beneficial to the target group through a scientific approach intended at being documented professionally and scientifically. As Hampton (1962), had experienced during a parent recruitment session for children of various diseases at a Children's Health Clinic, reluctance factors are a major issue facing the implementation of group psychotherapy interventions. A similar situation has been faced by researchers for the implementation of the PERKASA Intervention. There were parents who refused to participate in the study but informed that it was a good study for a vulnerable group like them.

This study proves that PERKASA Intervention is a dynamic processed. Rigorous planning as well as in-depth evaluation is required for improvement. The first dimension identified was that the rate of the number of respondents who agreed to participate in the study was low. However, the number of participants participated to test the feasibility and preliminary outcome is consistent with previous studies of parents of children who have been diagnosed with cancer (Kazak et al, 1999).

The impact of psychological changes on respondents participating in this study has been proven successful. After going through the planned sessions, level of stress, anxiety, depression have been successfully reduced, including increased of problem-focus use and an emotional-focus showed a decrease. In comparison, group psychotherapy methods are seen as more effective towards psychological distress than group of psycho-education intervention. These preliminary findings are seen as consistent with studies conducted by Shechtman and Gilat (2005), which proved that group interventions are better than education-type interventions. PERKASA Intervention has transformed the participants' belief system to manage their emotions and become more rational.

Another important dimension seen in this pilot study was the impact on the interaction of PERKASA Intervention and the personal factors of the participants. This can be seen through comparison effects between TG and CG post intervention. At this stage, some aspects tested did not show significant differences between groups. Therefore, it should be understood CG did not participate in PERKASA 
DOI: https://doi.org/10.47405/aswj.v7i1.197

Intervention are beyond the control of the researcher. Factors such as external activities, responsibilities or roles of each participant involved in the study influenced the impact on the variables tested (Jackson, 2009). In TG, the Medical Social Worker as an interventionist always focuses on group communication so that the client feels comfortable and not feeling isolated. Lee, Johnstone, and Herschman (2019), stated that psychotherapy will be successfully implemented because the interventionist always focuses to the client's verbal as well as respecting the client's cultural, values and beliefs. Respecting clients as individuals is a pivotal practice code as a Social Worker.

Participant's commitment in the interventions, especially from TG, seen to be the main cause for successful psychotherapy intervention. Although some of the parents were having time constraints, they still attended even in the short period of time to gain some knowledge and some experiences from other parents. Delivery system in group-based intervention is the success key and the for a support group (Papaikonomou, 2007). The knowledge transfer on the concept of A-B-C, belief system and consequences by interventionists during the session provides new perspectives and new knowledge to participants to implement coping strategies that tend towards more problem-focus strategies.

The efforts of the participant who participated in this intervention have successfully changed their belief system that led them to use adaptive behaviour (Houston \& Swords, 2021). Sense of confidence to Medical Social Worker as an interventionist was a success factor in this intervention. Jorgersen (2019), stated ability of Social Worker's to interact with a client's feelings and emotions is an important aspect during an intervention session. In addition, sense of inquisition of PERKASA Intervention as a whole, participants also seen interested in medical assistance that can be obtained from the Medical Social Worker during the intervention session. Other than conducting psychotherapy intervention sessions, other functions of Medical Social Workers in Malaysia are to seek assistance for patients, whether financial assistance to purchase certain drugs, hospital bills or assistance to purchase any medical equipment needed. Thus, participants view Medical Social Worker as the remarkable health provider units in the hospital setting.

Another factor seen to be success factors is the skills and micro skills of the Medical Social Worker while conducting group psychotherapy. Utilizing the Social Worker's skills during the intervention is the secret ingredient of PERKASA Intervention. Every Social Worker in the hospital setting is compulsory to understand the medical model that is used simultaneously with the Social Work models and theories. According to Katz, McPartland, and Rines (2021), skills and micro skills need to be applied simultaneously during service delivery to drive more dynamic social work practice. As a practitioner in a hospital that performs direct service to clients, the Medical Social Worker needs to synergize micro skills and skills that are used to help clients.

\section{Limitation}

A few limitations were identified during the implementation of this study. Firstly, short period of time to identify target group. Secondly, this intervention is voluntarily based and the first to be implemented in Malaysia, it is difficult to convince parents that there is no legal bond or interference with the treatment of their children when participating in this study. Third, the absence of empirical references within the country makes it difficult for researchers to refer the best methods of performing group psychotherapy interventions on parents of children with leukaemia. Fourth, small number of samples in the study disrupted the report to be presented to policy makers to make PERKASA Intervention a permanent program in future.

\section{Conclusion}

Therefore, it can be concluded the pilot study of PERKASA Intervention was successful and appropriate. To the knowledge of researchers, this study is the first group psychotherapy intervention among parents of leukaemia children conducted by Medical Social Worker in Malaysia. Nevertheless, 
DOI: https://doi.org/10.47405/aswj.v7i1.197

some new aspects and approaches need to be reassessed to ensure that similar studies in the future can be implemented more smoothly.

\section{References}

Ambigga Devi, K., Sherina, M. S., \& Suthahar, A. (2005). Depression and anxiety among family caregivers of cancer patients in an oncology clinic. Malaysian Journal of Psychiatry, 13(1), $35-42$.

American Academy of Pediatrics, (1997). Guideline for the pediatric cancer center and the role of such centers in diagnosis and treatment. Pediatrics, 99, 139-140.

Anclair, M., Lappalainen, R., Muotka, J., \& Hiltunen, A. J., (2018). Cognitive behavioural therapy and mindfulness for stress and burnout: a waiting list controlled pilot study comparing treatments for parents of children with chronic conditions. Scandinavian Journal Of Caring Sciences, 32(1), 38dep9-396.

Aracena, M., Gomez, E., Undurraga, C., Leiva, L., Marinkovic, K., \& Molina, Y., (2016). Validity and reliability of the Parenting Stress Index Short Form (PSI-SF) applied to a Chilean sample. Journal of Child and Family Studies, 25(12), 3554-3564.

Barrera, M., Atenauem, E., Doyle, J., Berlin-Romalis, D., \& Hancock, K. (2012). Differences in mothers' and fathers' psychological distress after pediatric SCT: a longitudinal study. Bone marrow transplantation, 47(7), 934.

Bilani, N., Jamali, S., Chahine, A., Zorkot, M., Homsi, M., Saab, M., Saab, R., Nabulsi, M., \& Chaaya, M. (2019). Illness cognition and health anxiety in parents of children with cancer. Journal of psychosocial oncology, 37(6), 713-728.

Carver, C. S. (1997). You want to measure coping but your protocol'too long: Consider the brief cope. International Journal of Behavioral Medicine, 4(1), 92.

Din, S. H. S., Jaafar, N. R. N., Zakaria, H., Saini, S. M., Ahmad, S. N. A., \& Midin, M., (2017). Anxiety disorders in family caregivers of breast cancer patients receiving oncologic treatment in Malaysia. Asian Pacific Journal of Cancer Prevention: APJCP, 18(2), 465.

Di Battista, A., Dupuis, L. L., Cassidy, M., Portwine, C., Johnston, D. L., Pradier Silva, M., Sung, L., \& Barrera, M. (2017). Parent attributions about child symptoms related to cancer therapy. Journal of Pediatric Oncology Nursing, 34(1), 44-50.

Ellis, A., (1995). Changing rational-emotive therapy (RET) to rational emotive behavior therapy (REBT). Journal of Rational-Emotive \& Cognitive-Behavior Therapy, 13(2), 85-89.

Farmer, A. Y., \& Lee, S. K., (2011). The effects of parenting stress, perceived mastery, and maternal depression on parent-child interaction. Journal of Social Service Research, 37(5), 516-525.

Haegen, M. V., \& Luminet, O. (2015). Stress, psychosocial mediators, and cognitive mediators in parents of child cancer patients and cancer survivors: attention and working memory pathway perspectives. Journal of Psychosocial Oncology, 33(5), 504-550.

Hampton, P. J. (1962). Group psychotherapy with parents. American Journal of Orthopsychiatry, 32(5), 918.

Hoekstra-Weebers, J. E., Wijnberg-Williams, B. J., Jaspers, J. P., Kamps, W. A., \& van de Wiel, H. B., (2012). Coping and its effect on psychological distress of parents of pediatric cancer patients: a longitudinal prospective study. Psycho-Oncology, 21(8), 903-911.

Houston, S., \& Swords, C. (2021). Analysing a parent's capacity to change: towards a model for child protection social workers. Journal of Social Work Practice, 35(3), 231-244.

Jackson, S. L., (2009). Research methods and statistics: A critical thinking approach (3 ${ }^{\text {rd }}$ ed.). California: Wardworth, CENGAGE Learning.

Jobe-Shields, L., Alderfer, M. A., Barrera, M., Vannatta, K., Currier, J. M., \& Phipps, S., (2009). Parental depression and family environment predict distress in children prior to stem- cell transplantation. Journal of developmental and behavioral pediatrics, 30(2), 140.

Jorgensen, S. (2019). Exploring emotional aspects of care and control in social work with children and families-a single case analysis of conversation. Journal of Social Work Practice, 33(4), 385402.

Katz, E., McPartland, S., \& Rines, J. (2021). Exploring micro-skills as the underpinnings of effective social work practice. Journal of Social Work Practice, 35(2), 177-190. 
DOI: https://doi.org/10.47405/aswj.v7i1.197

Kazak, A. E., Simms, S., Barakat, L., Hobbie, W., Foley, B., Golomb, V., \& Best, M. (1999). Surviving Cancer Competently Intervention Program (SCCIP): a cognitive-behavioral and family therapy intervention for adolescent survivors of childhood cancer and their families. Family process, 38(2), 176-191.

Kearney, J. A., Salley, C. G., \& Muriel, A. C. (2015). Standards of psychosocial care for parents of children with cancer. Pediatric Blood \& Cancer, 62(S5), S632-S683.

Kohlsdorf, M., \& Costa Junior, Á. L. (2011). Coping strategies and caregiver's anxiety in pediatricon cohematology. Psicologia: Reflexão e Crítica, 24(2), 272-280.

Kostak, M. A., \& Avci, G., (2013). Hopelessness and depression levels of parents of children with cancer. Asian Pacific Journal of Cancer Prevention, 14(11), 6833-6838.

Kurtz, B. P., \& Abrams, A. N., (2010).Psychiatric aspects of pediatric cancer. Child and Adolescent Psychiatric Clinics, 19(2), 401-421.

Lakkis, N. A., Khoury, J. M., Mahmassani, D. M., Ramia, M. S., \& Hamadeh, G. N. (2016). Psychological distress and coping strategies in parents of children with cancer in Lebanon. Psycho-Oncology, 25(4), 428-434.

Lazarus, R. S., \& Folkman, S., (1984). Stress, appraisal, and coping.New York: Springer Publishing Company.

Lee, E., Johnstone, M., \& Herschman, J. (2019). Negotiating therapy goals and tasks in cross-cultural psychotherapy. Journal of Social Work Practice, 33(4), 447-462.

Lin, P. L., \& Wong, S. Y. (2012). The reliability of the malay versions of hospital Anxiety depression scale (HADS) and McGill Quality Of Life Questionnaire (MQOL) among a Group of Patients with Cancer in Malaysia. Malaysian Journal of Psychiatry, 21(1).

Loyd, B. H., \& Abidin, R. R., (1985). Revision of the parenting stress index. Journal of Pediatric Psychology, 10(2), 169-177.

Marsland, A. L., Long, K. A., Howe, C., Thompson, A. L., Tersak, J., \& Ewing, L. J., (2013). A pilot trial of a stress management intervention for primary caregivers of children newly diagnosed with cancer: preliminary evidence that perceived social support moderates the psychosocial benefit of intervention. Journal of Pediatric $\quad$ Psychology, 38(4), 449-461

Masa'Deh, R., Collier, J., \& Hall, C., (2012). Parental stress when caring for a child with cancer in Jordan: a cross-sectional survey. Health and quality of life outcomes, 10(1), 88.

McLoone, J. K., Wakefield, C. E., Yoong, S. L., \& Cohn, R. J., (2013). Parental sleep experiences on the pediatric oncology ward. Supportive care in cancer, 21(2), 557-564.

Myers, R. M., Balsamo, L., Lu, X., Devidas, M., Hunger, S. P., Carroll, W. L., Winick, N. J., Maloney, K.W., \& Kadan-Lottick, N. S., (2014). A prospective study of anxiety, depression, and behavioral changes in the first year after a diagnosis of childhood acute lymphoblastic leukemia: a report from the Children's Oncology Group. Cancer, 120(9), 1417-1425.

National Cancer Institute (n.d.). Research-Tested Intervention Programs (RTIPs). Retrieved January 25 2021, from https://rtips.cancer.gov/rtips/programDetails.do?programId=102875

National Cancer Registration Report 2012-2016, (2019). Putrajaya: Malaysia Ministry of Health

Norberg, A. L., \& Steneby, S. (2009). Experiences of parents of children surviving brain tumour: a happy ending and a rough beginning. European Journal of Cancer Care, 18(4), 371-380.

Nur Saadah, M. A., Siti Hajar, A. B., \& Islam, M. R., (2014). Coping strategies among mothers of chronically ill children: A case study in Malaysia. Journal of Social Service Research, 40(2), 160-177.

Osborne, L. A., McHugh, L., Saunders, J., \& Reed, P., (2008). A possible contra-indication for early diagnosis of Autistic Spectrum Conditions: Impact on parenting stress. Research in autism spectrum disorders, 2(4), 707-715.

Othman, A., Blunden, S., Mohamad, N., Mohd Hussin, Z. A., \& Jamil Osman, Z. (2010).Piloting a psycho-education program for parents of pediatric cancer patients in Malaysia. PsychoOncology: Journal of the Psychological, Social and Behavioral Dimensions of Cancer, 19(3), 326-331.

Othman, A., Mohamad, N., Hussin, Z. A., \& Blunden, S. (2011a). Factors related to parental well being in children with cancer (Doctoral dissertation, IACSIT-Internal Association of Computer Science). 
DOI: https://doi.org/10.47405/aswj.v7i1.197

Othman, A., Mohamad, N., Hussin, Z. A., \& Blunden, S., (2011b). Psychological distress and associated factors in parents of children with cancer. International Journal of Social Science and Humanity, 1(1), 37-42.

Papaikonomou, M. (2007). Childhood cancer: a parent's perspective on social support, with a case illustration. Journal of child and adolescent mental health, 19(1), 65-73.

Prime Minister Media Statement Office (28 May 2021). Putrajaya: Malaysia

Rosenberg, A. R., Dussel, V., Kang, T., Geyer, J. R., Gerhardt, C. A., Feudtner, C., \& Wolfe, J.,(2013). Psychological distress in parents of children with advanced cancer. JAMA pediatrics, 167(6), 537-543.

Rosenberg, A. R., Wolfe, J., Bradford, M. C., Shaffer, M. L., Yi-Frazier, J. P., Curtis, J. R., Syrjala, K. L., \& Baker, K. S. (2014).Resilience and psychosocial outcomes in parents of children with cancer. Pediatric blood \& cancer, 61(3), 552-557.

Shechtman, Z., \& Gilat, I. (2005). The effectiveness of counseling groups in reducing stress ofparents of children with learning disabilities. Group Dynamics: Theory, Research, and Practice, 9(4), 275.

Shuib, N. H., (12 Januari 2020). Kanak-kanak derita kanser. Retrieved Mac 10 2021, from https://www.bharian.com.my/wanita/sihat/2020/01/646056/kanak-kanak-derita-kanser

Stewart, B. W. K. P., \& Wild, C. P., (2014). World cancer report 2014.

Sutan, R., Al-Saidi, N. A., Latiff, Z. A., \& Ibrahim, H. M., (2017). Coping strategies among parents of children with acute lymphoblastic leukemia. Health, 9(07), 987.

van der Geest, I. M., van den Heuvel-Eibrink, M. M., Passchier, J., van den Hoed-Heerschop, C., Pieters, R., \& Darlington, A. S. E., (2014). Parenting stress as a mediator of parents' negative mood state and behavior problems in children with newly diagnosed cancer. PsychoOncology, 23(7), 758-765.

Warner, E. L., Kirchhoff, A. C., Nam, G. E., \& Fluchel, M., (2014). Financial burden of pediatric cancer for patients and their families. Journal of Oncology Practice, 11(1), 12-18.

Watanabe, A., Nunes, T., \&Abreu, G. D., (2014). Japanese parents' perception of disclosing the diagnosis of cancer to their children. Clinical child psychology and psychiatry, 19(1), $125-$ 138.

Wikman, A., Mattsson, E., von Essen, L., \& Hovén, E., (2018). Prevalence and predictors of symptoms of anxiety and depression, and comorbid symptoms of distress in parents of childhood cancer survivors and bereaved parents five years after end of treatment or a child's death. Acta Oncologica, 57(7), 950-957.

Williams, L. K., McCarthy, M. C., Eyles, D. J., \& Drew, S., (2013). Parenting a child with cancer: Perceptions of adolescents and parents of adolescents and younger children following completion of childhood cancer treatment. Journal of Family Studies, 19(1), 80-89.

Zarina, A. L., Radhiyah, R., Hamidah, A., Rahman, J., \& Syed Zulkifli, S., Z., (2012). $\quad$ Parenting stress in Childhood Leukaemia. Medicine and Health, 7(2), 73-83.

Zigmond, A. S., \& Snaith, R. P., (1983). The hospital anxiety and depression scale. Acta Psychiatrica Scandinavica, 67(6), 361-370. 